\title{
Determination of position of hydraulic jump in a flume by using CFD and comparison with experiential results
}

https://doi.org/10.21698/rjeec.2020.211

Proceedings Paper

\author{
ALI YILDIZ, ALI IHSAN MARTI, ALPASLAN YARAR, VOLKAN YILMAZ
}

Konya Technical University, Civil Engineering Department, Turkey

*Corresponding author (e-mail): ayildiz@ktun.edu.tr

\begin{abstract}
Dams and hydraulic structures are used for the supply and control of water, which have great importance on human life. The sluice gate is one of the hydraulic control structures. Sluice gates release excess water from the reservoir to the downstream side in a controlled manner with a certain discharge for controlling the level of the reservoir. A hydraulic jump is created to dissipate the energy of flow coming from under the gates. A hydraulic jump occurs when the flow regime is changed from subcritical to supercritical. However, the position of the hydraulic jump in the channel should be known exactly to prevent damage to surrounding structures. In this study, an open channel system with a sluice gate is used to produce a hydraulic jump. Experiments are conducted for two different gate openings $\left(a_{1}=1.5 \mathrm{~cm}\right.$ and $\left.a_{2}=2 \mathrm{~cm}\right)$ and 16 discharge values. For each case, the position of the hydraulic jump is determined. In addition, flow depths at 5 different points were measured including before and after the hydraulic jump. The results obtained from the experimental study were compared with the numerical model in terms of the position of hydraulic jump and flow depths. According to the results obtained, the numerical model and the physical model showed between 80 and $91 \%$ consistency.
\end{abstract}

Keywords: ANSYS-Fluent, hydraulic jump, numerical modelling, physical modelling, sluice gate

\section{INTRODUCTION}

Dams are large-sized obstacle structures from different materials and different types creating reservoirs and lakes by preventing delaying or directing the flow of water. Since water is an important natural resource for human, animal, and plant life, therefore studies for water usage started with the existence of human beings. The dams built for many purposes consist of parts such as body, reservoir, spillway, bottom intake structure, and power generation facility. Besides, depending on the purpose of the construction, there may be additional structures such as sand trap pools and energy production plants.

Spillways are structures that transfer the excess water coming from the reservoir downstream in a safe and controlled manner. Sluice gates accumulate the water behind them and the water level is kept at a maximum level in the reservoir [1]. When sluice gates are not designed correctly, there may be collapses and breaks due to the high amount of water pressure (Fig. 1). $22 \%$ of the dam failures are due to insufficient spillway capacities or improper operation [2].
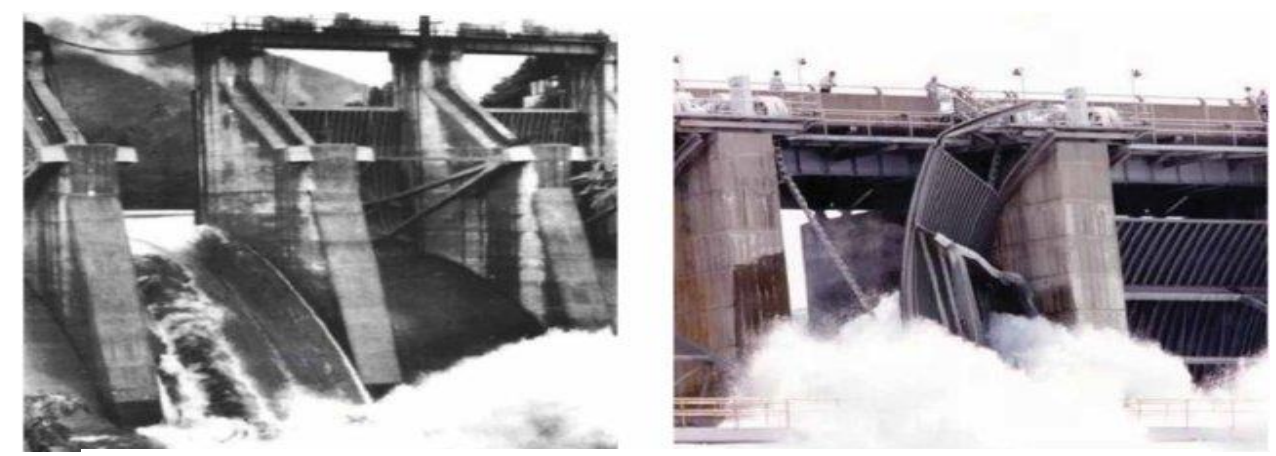

Fig. 1. Sluice gate failures (first Japan 1967 and second USA 1995) 
Energy dissipation structures that built the end of spillways dissipate the energy of flow and provide a transition between downstream and spillway. Energy dissipation structures provide a hydraulic jump to dissipate some of the energy of flow and allowing water to pass to the river bed with the subcritical flow. Determining the position of the hydraulic jump is very important. The hydraulic jump must occur in a designated area inside the energy dissipation pool. An unpredictable hydraulic jump can damage structures around it [3].

Gharangik and Chaudhry [3] investigated a hydraulic jump by a numerical model. They applied the Boussesq equations to simulate both the sub and supercritical flows and a hydraulic jump in a rectangular channel having a small bed slope. Ead and Rajaratnam [4] studied hydraulic jumps on a corrugated bed experimentally with Froude numbers from 4 to 10. Sarker and Rhodes [5] studied hydraulic jump on a smooth bed by physical and numerical methods.

\section{MATERIALS AND METHODS}

\section{Sluice Gates}

Sluice gates keep water at the maximum level at the reservoir and evacuate excessive water when necessary. In addition, sluice gates are used to hold floating objects such as ice and wood from passing downstream. Depending on

the opening of the sluice gate, it is necessary to determine the speed of flow passing under the gate. Sluice gates can be placed on spillways and open channels (Fig. 2).

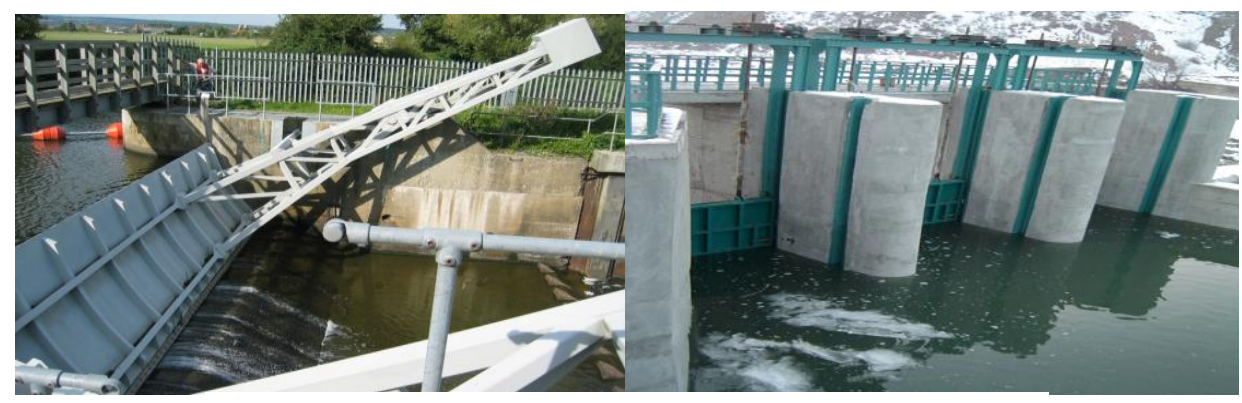

Fig. 2. Radial sluice gates and vertical sluice gates

Flow under a sluice gate can be examined in two conditions. These are:

1-Free flow condition: Flow passing under the gate is open the atmosphere with the supercritical flow. The depth of flow is smaller than the gate opening (a). A hydraulic jump may occur away from the gate.

2-Submerged flow condition: Hydraulic jump caused by the flow is formed adjacent to the sluice gate. The depth of the flow is higher than the gate opening (a) and flow passing under the gate is not open to the atmosphere. A high amount of heat loss occurs because of high turbulences and backflow effects. Free and submerged flow conditions in the sluice gate can be seen in Figure 3.

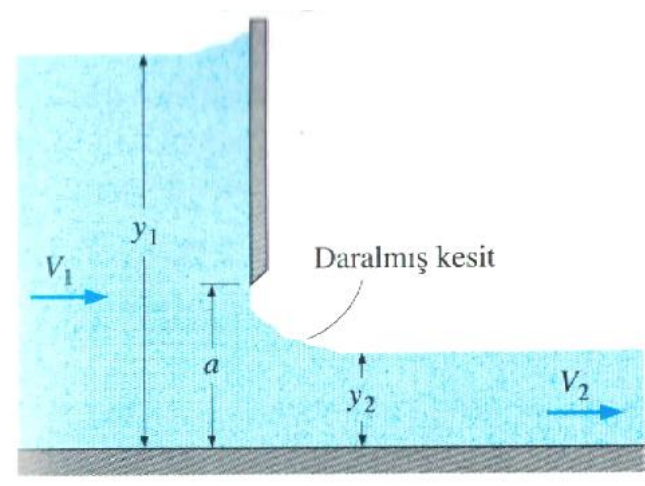

(a)

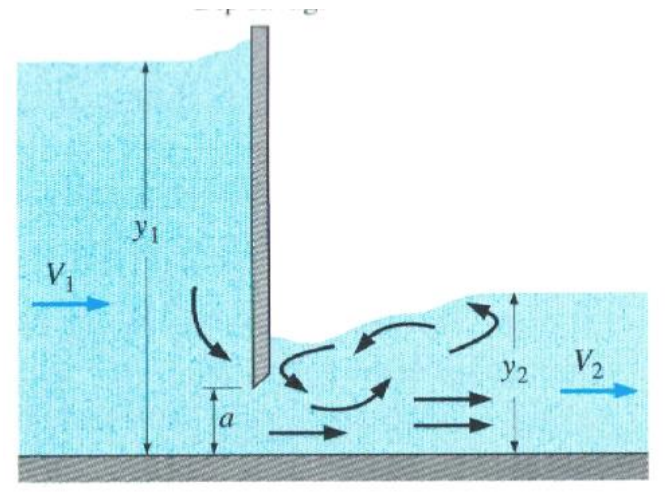

(b)

Fig. 3. a) Free flow condition and b) submerged flow condition 
Discharge passing under the sluice gate is calculated by the Eq. 1 [7]:

$$
Q=C_{d}^{*} a * b * \sqrt{2 * g * y_{1}}
$$

where $Q$ is the discharge $\left(\mathrm{m}^{3} / \mathrm{sn}\right), C_{d}$ is the discharge coefficient, a is the gate opening $(\mathrm{m})$, $b$ is the width of the gate $(\mathrm{m}), y$ is the flow depth in the upstream side, $C_{d}$ coefficient is determined by Figure 4.

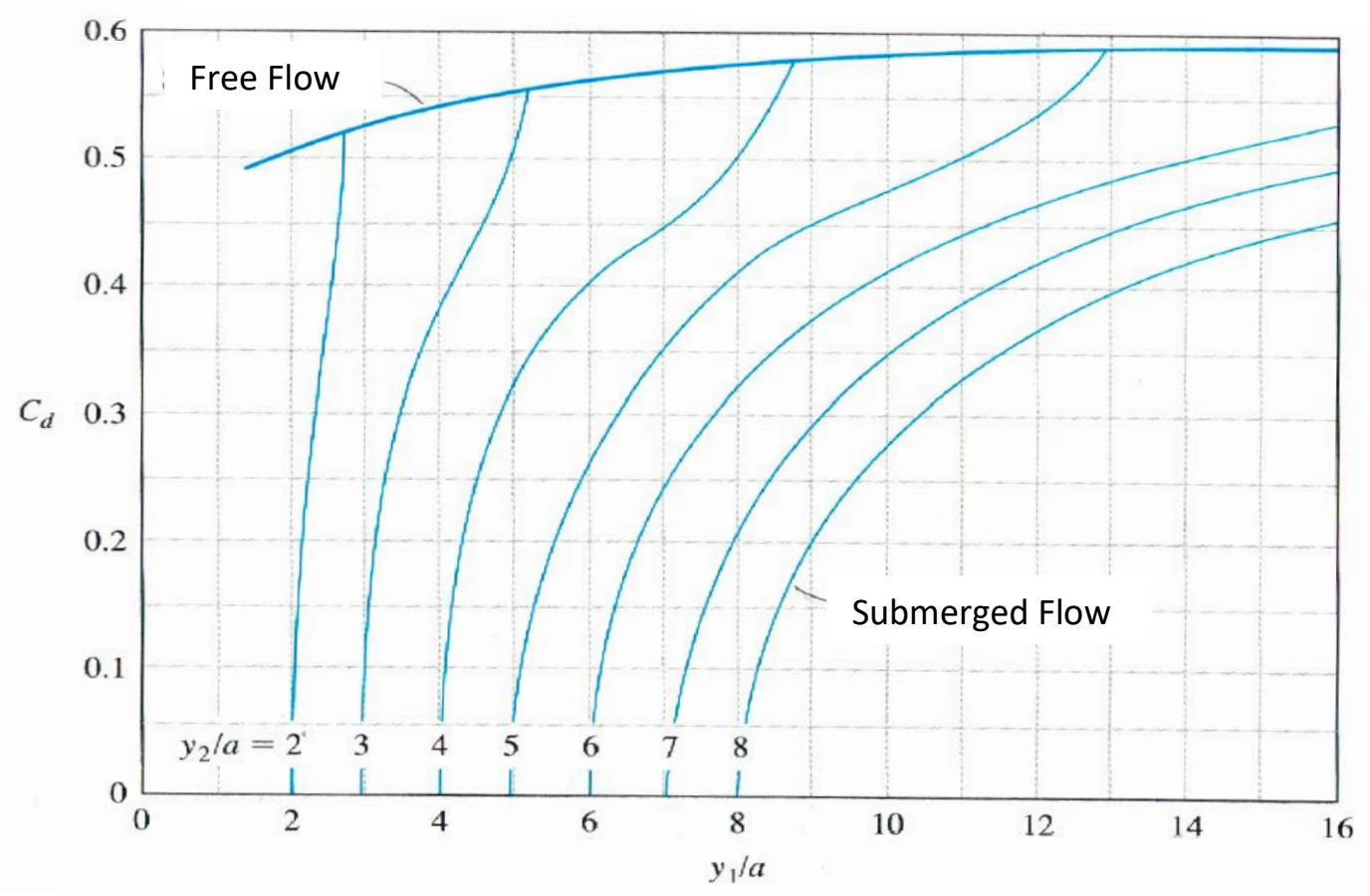

Fig. 4. Free flow condition and submerged flow condition

\section{Hydraulic Jump}

The hydraulic jump occurs when water enters turbulence while the flow regime changed from subcritical to supercritical. Hydraulic jump poses a great danger when it occurs uncontrolled in open channels because there are great forces that arise and the depth of flow rises after the jump (Fig. 5). When the hydraulic jump is controlled, it provides benefits. For example, water released from spillways flow with a very high amount of energy and cause in erosions in the river bed. These deposits and carrying materials accumulated on one side and disrupt the arrangement of the bed. However, after water released from the spillway, a controlled hydraulic jump will decrease the energy of the flow, and transportation of water will be easier and safer.

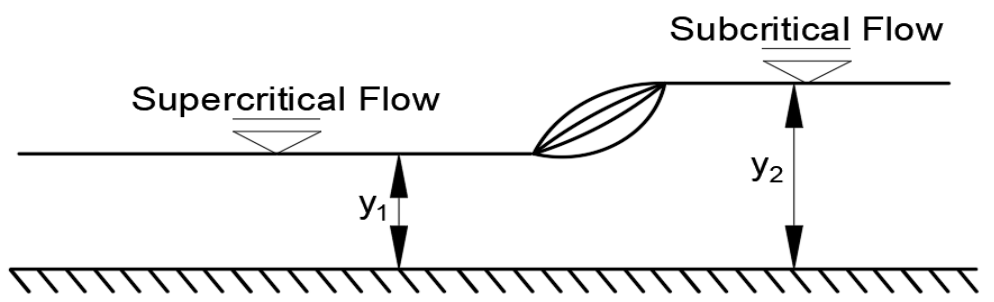

Fig. 5. General scheme of hydraulic jump

Flow depths after a hydraulic jump $\left(\mathrm{y}_{2}\right)$ in hydraulic jump calculated by Eq. 3: calculated by Eq. 2 and dissipated energy $(\Delta \mathrm{H})$ 


$$
\begin{aligned}
& y_{2}=\frac{y_{1}}{2} *\left(\sqrt{1+8 * F_{r_{1}}}-1\right) \\
& \Delta H=\frac{\left(y_{1}+y_{2}\right)^{3}}{4 y_{1} y_{2}}
\end{aligned}
$$

where $y_{1}$ is the flow depths before the hydraulic jump, $y_{2}$ is the flow depths after the hydraulic jump, $F_{r l}$ is the Froude number in supercritical

\section{ANSYS-Fluent}

The numerical model of the hydraulic jump is created by ANSYS-Fluent. It is possible to analyze Ansys-Fluent with Navier Stokes equations using fluid (VOF) multi-phase modeling methods and obtain values such as pressure, velocity, water profile of the fluid. The calculation area is divided into small cells with the help of hexahedral and tetrahedral grids. The ratio of solution to reality increases

$$
\frac{\partial \rho}{\partial t}+\Delta *(\rho v)=S_{m}
$$

For 2D axisymmetric geometries, the continuity

$$
\frac{\partial \rho}{\partial t}+\frac{\partial}{\partial x}\left(\rho v_{x}\right)+\frac{\partial}{\partial x}\left(\rho v_{r}\right)+\frac{\rho v_{r}}{r}=S_{m}
$$

Conservation of momentum in an inertial (non-

$$
\frac{\partial}{\partial t}(\rho v)+\Delta(\rho v v)=-\Delta *^{*} p+\Delta \tau+\rho g+F
$$

where $x$ is the axial coordinate, $r$ is the radial coordinate, $v_{x}$ is the axial velocity, $v_{r}$ is the radial velocity, $\rho$ is the density of the fluid, $p$ is

\section{Physical Modeling}

The sluice gate is placed in an open channel system, which has $400 \mathrm{~cm}$ length, $7.5 \mathrm{~cm}$ width, and $15 \mathrm{~cm}$ height. Discharge is measured by the help of a tank. Discharge is calculated by measuring the change of the volume in the tank over time. Flow rates between 0 and 4 lt/sn can be provided in the channel. The test flume is made of roughness plastic and has zero slopes. The experimental setup used in the tests can be seen in Figure 6. The flume had a closed-loop water system and the flow to the flume was supplied from a constant head water tank by a pump. Water coming from the pipe caused waving and three screens were placed upstream of the channel. The screens are behaving as due to the size of the mesh so, meshing is important in creating a simulation. The ratio of solution to reality increases due to the size of the mesh so, meshing is important in creating simulation [8]. ANSYS-Fluent solves conservation equations for mass and momentum.

The equation for conservation of mass, or continuity Eq. 4:

equation is given by Eq. 5:

accelerating) reference frame is described by Eq.6:

the pressure, $g$ is the gravity, $F$ is the body force and $\tau$ is the stress tensor.

filters, which act as a breakwater and provide a smooth profile before the sluice gate.

The sluice gate is placed on the head of the channel (Fig. 6). Water accumulates behind the sluice gate and is released under the gate. To make a hydraulic jump after the gate, a step is placed $240 \mathrm{~cm}$ away from the gate. Just before the step flow is subcritical and coming flow under the gate is supercritical, therefore a hydraulic jump occurs between gate and step. Experiments were repeated for two different gate opening and $(\mathrm{a}=1.5 \mathrm{~cm}$ and $\mathrm{a}=2 \mathrm{~cm}) 16$ different discharge values. The position of the hydraulic jump is determined for each case. Also, flow depths are measured for five 
different points (Fig. 7).

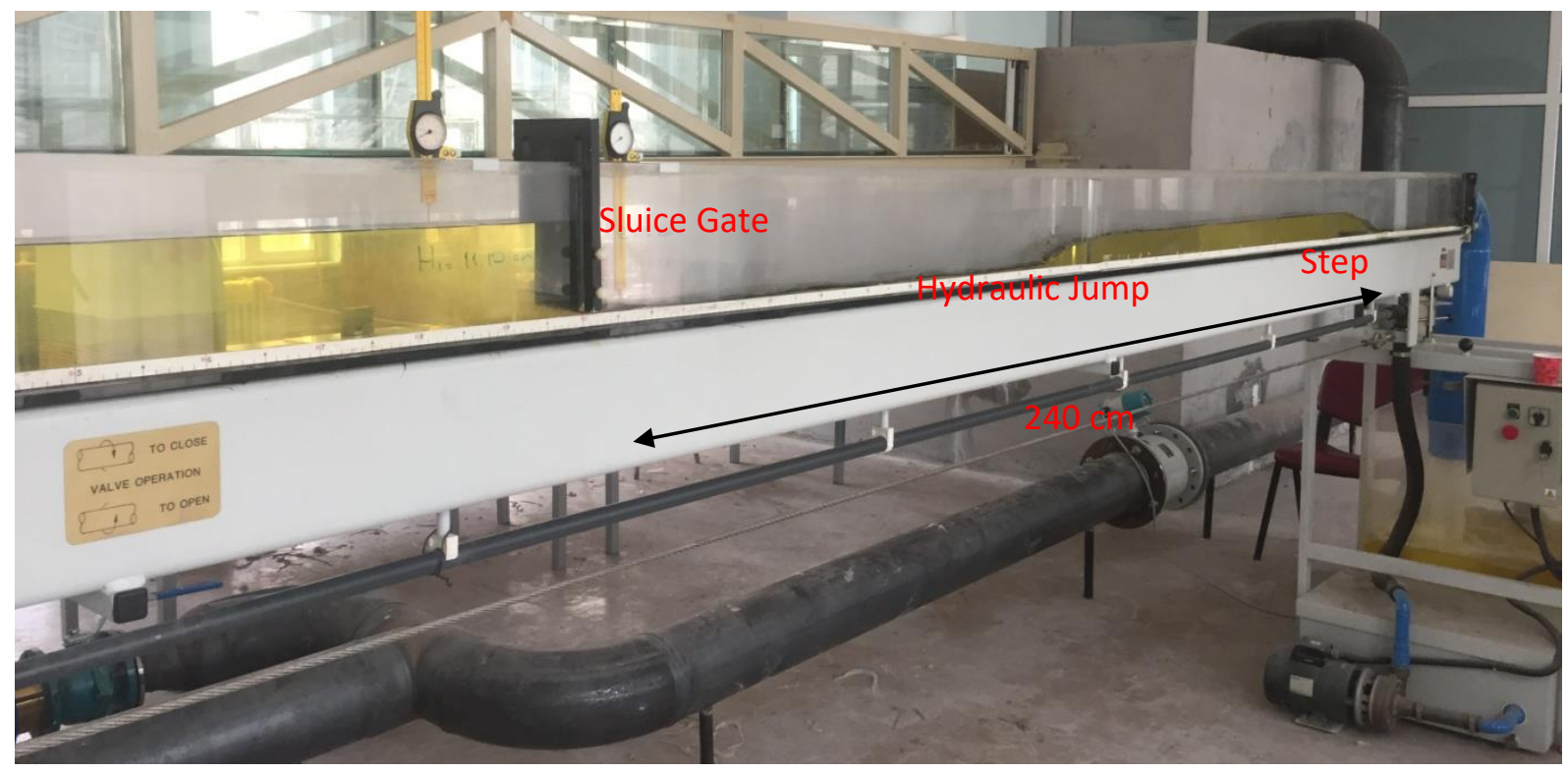

Fig. 6. General view of the open channel system

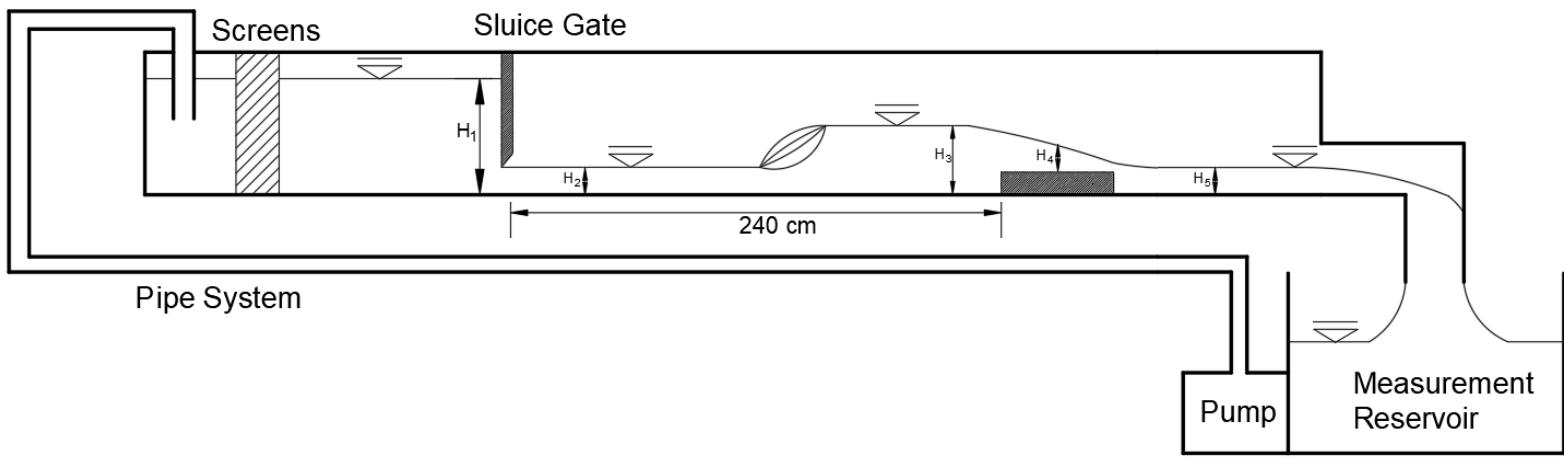

Fig. 7. General scheme of the experimental setup

\section{Numerical Modeling}

Numerical modeling was done by ANSYSFluent. In numerical modeling, to obtain the closest results with experiments, the initial conditions should be a similar environment of experimental study. A numerical model in Fluent created in 5 steps; they are 1-Geometry section which solid geometry of the model is Geometry and Meshing:

The model was created in 2-D dimensions. The size of the mesh used is $5 \mathrm{~mm}$. The face Setup:

In this section, the model is prepared for analysis following the initial condition of the physical model. The inlet of flow volume is defined as mass flow inlet in terms of $\mathrm{kg} / \mathrm{s}$ or Solution:

An analysis took approximately 3 hours. At the end of the analysis, besides comparison of flow created, 2- Mesh section where the mesh method is chosen and mesh size is defined, 3Setup section where the initial condition of the numerical model is defined, and finally Result section where results, visualized and images are taken.

meshing method was used. A total 32950 mesh (elements) is used for a solution (Fig. 8).

1t/s. K-omega RNG was used as a turbulence model. Flow volume is defined as containing 2 fluids, air, and water (Fig. 8).

depths, also the position of the hydraulic jump also comprised. 


\begin{tabular}{|c|c|c|}
\hline \multicolumn{3}{|c|}{ Details of "Mesh" } \\
\hline \multirow{7}{*}{$\oplus$} & \multicolumn{2}{|l|}{ Display } \\
\hline & \multicolumn{2}{|l|}{ Defaults } \\
\hline & Physics Preference & CFD \\
\hline & Solver Preference & Fluent \\
\hline & Relevance & 0 \\
\hline & Export Format & Standard \\
\hline & Element Midside Nodes & Dropped \\
\hline \multirow[t]{12}{*}{$\square$} & \multicolumn{2}{|l|}{ Sizing } \\
\hline & Size Function & Curvature \\
\hline & Relevance Center & Coarse \\
\hline & Initial Size Seed & Active Assembly \\
\hline & Span Angle Center & Fine \\
\hline & $\square$ Curvature Normal A... & Default $\left(18,0^{\circ}\right)$ \\
\hline & $\square$ Min Size & $5, e-003 \mathrm{~m}$ \\
\hline & $\square$ Max Face Size & $5, e-003 \mathrm{~m}$ \\
\hline & $\square$ Growth Rate & Default $(1,20)$ \\
\hline & Automatic Mesh Base... & On \\
\hline & $\square$ Defeature Size & Default $(2,5 \mathrm{e}-003 \mathrm{~m})$ \\
\hline & Minimum Edge Length & $2,1213 e-002 \mathrm{~m}$ \\
\hline$\oplus$ & \multicolumn{2}{|l|}{ Quality } \\
\hline$\oplus$ & \multicolumn{2}{|l|}{ Inflation } \\
\hline+ & \multicolumn{2}{|l|}{ Assembly Meshing } \\
\hline$\oplus$ & \multicolumn{2}{|l|}{ Advanced } \\
\hline$\square$ & \multicolumn{2}{|l|}{ Statistics } \\
\hline & Nodes & 33861 \\
\hline & Elements & 32950 \\
\hline
\end{tabular}

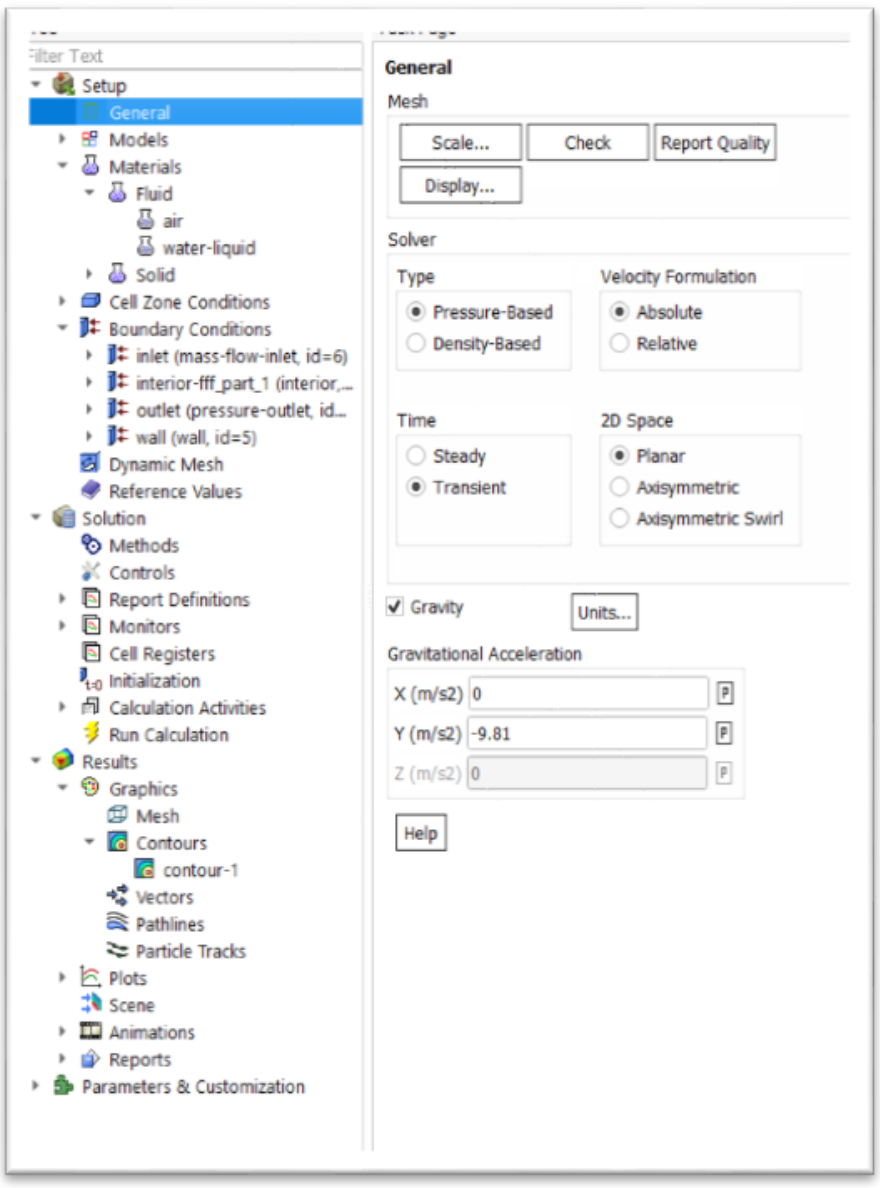

Fig. 8. Mesh and solution setup of fluent

\section{RESULTS AND DISCUSSION}

Results obtained from experiments are given in Tables 1 and 2. Experiments are conducted for 2 different gate openings and 16 different discharge values. Flow depths for five different points are measured. When results are examined, unlike the other flow depths, flow depth-2 $\left(\mathrm{H}_{2}\right)$ decreased while discharge increased. The reason for this is that as discharge increased, the water level at the reservoir increased and flow under the gate passes with a higher speed. The height decreases as the water velocity increases. It can also be seen from the results that as the discharge increases, the position of the hydraulic jump changes. As the flow increases, the hydraulic approaches the step, and when the discharge decreases, the hydraulic jump approaches the gate. The reason for this hydraulic jump is caused by the balances of body forces and momentum. When the discharge increased, velocity also increased and the hydraulic jump moves away from the gate.

Table 1. Experimental study results, part 1

Gate Opening e $=1.5 \mathrm{~cm}$

\begin{tabular}{ccccccc}
\hline $\begin{array}{c}\text { Flow Dep. at } \\
\text { Point- } 1, \mathrm{H}_{1}\end{array}$ & $\begin{array}{c}\text { Flow Dep. at } \\
\text { Point-2, } \mathrm{H}_{2}\end{array}$ & $\begin{array}{c}\text { Flow Dep. at } \\
\text { Point-3, } \mathrm{H}_{3}\end{array}$ & $\begin{array}{c}\text { Flow Dep. at } \\
\text { Point-4, } \mathrm{H}_{4}\end{array}$ & $\begin{array}{c}\text { Flow Dep. at } \\
\text { Point-5, } \mathrm{H}_{5}\end{array}$ & $\begin{array}{c}\text { Pos. of Hyd. } \\
\text { Jump }\end{array}$ & Q \\
\hline 3.60 & 1.20 & 5.30 & 1.62 & 1.00 & 1.18 & 0.61 \\
4.65 & 1.17 & 5.62 & 1.80 & 1.15 & 1.35 & 0.71 \\
5.38 & 1.15 & 5.83 & 1.90 & 1.25 & 1.40 & 0.77 \\
5.70 & 1.10 & 5.90 & 2.00 & 1.30 & 1.47 & 0.81 \\
7.75 & 1.05 & 6.25 & 2.15 & 1.40 & 1.65 & 0.95 \\
8.73 & 1.00 & 6.40 & 2.40 & 1.50 & 1.77 & 1.02 \\
11.05 & 0.95 & 6.70 & 2.48 & 1.60 & 1.94 & 1.16 \\
11.75 & 0.90 & 6.85 & 2.80 & 1.70 & 2.02 & 1.21 \\
15.30 & 1.00 & 7.10 & 3.00 & 1.90 & 2.25 & 1.36 \\
\hline
\end{tabular}


Gate Opening e $=1.5 \mathrm{~cm}$

Table 2. Experimental study results, part 2

\begin{tabular}{ccccccc}
\hline $\begin{array}{c}\text { Flow Dep. at } \\
\text { Point-1, } \mathrm{H}_{1}\end{array}$ & $\begin{array}{c}\text { Flow Dep. at } \\
\text { Point-2, } \mathrm{H}_{2}\end{array}$ & $\begin{array}{c}\text { Flow Dep. at } \\
\text { Point-3, } \mathrm{H}_{3}\end{array}$ & $\begin{array}{c}\text { Flow Dep. at } \\
\text { Point-4, } \mathrm{H}_{4}\end{array}$ & $\begin{array}{c}\text { Flow Dep. at } \\
\text { Point-5, } \mathrm{H}_{5}\end{array}$ & $\begin{array}{c}\text { Pos. of Hyd. } \\
\text { Jump }\end{array}$ & Q \\
\hline 4.75 & 1.60 & 6.13 & 2.17 & 1.40 & 1.27 & 0.91 \\
6.60 & 1.40 & 6.60 & 2.55 & 1.60 & 1.51 & 1.11 \\
8.45 & 1.23 & 6.95 & 2.85 & 1.75 & 1.72 & 1.28 \\
10.30 & 1.30 & 7.30 & 3.10 & 1.95 & 1.90 & 1.43 \\
11.10 & 1.27 & 7.40 & 3.20 & 2.00 & 1.98 & 1.45 \\
12.15 & 1.30 & 7.55 & 3.30 & 2.15 & 2.09 & 1.53 \\
14.15 & 1.35 & 7.80 & 3.55 & 2.25 & 2.22 & 1.65 \\
\hline
\end{tabular}

In the next phase of the study, the numerical modeling section, the same physical model created in the computer environment. The same discharges values with the experiments were entered in the numerical model and analyzes were made for different discharge values and gate openings. At the end of each analysis, the position of the hydraulic jump, flow depths, and water surface profiles were compared. Only results of the gate opening $\mathrm{a}=2 \mathrm{~cm}$ are given. As can be seen from Figure 9, there is a high degree of similarity between the physical model and the numerical model. The numerical model has successfully determined the position of the hydraulic jump with the worst $80 \%$ and the best 91\% consistency with the physical model. Hydraulic jump has successfully exhibited the behaviors in the experimental study displayed in the numerical model. It is possible to improve the success of the numerical model with different turbulence models and initial conditions. Also, the water surface profile of the numerical model and physical model are compared. The purpose of comparing the flow profiles is to determine how the flow profiles of the physical model and numerical model consistent with each other.

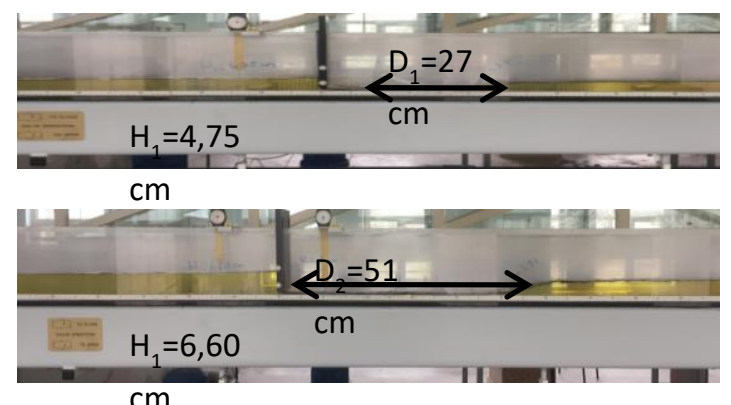

$\mathrm{cm}$

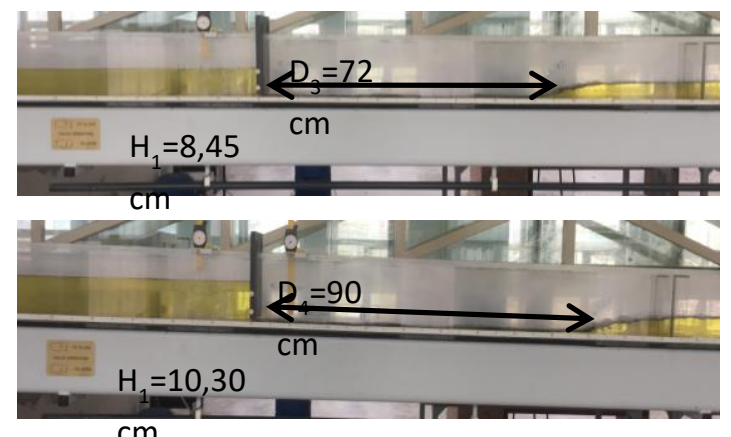

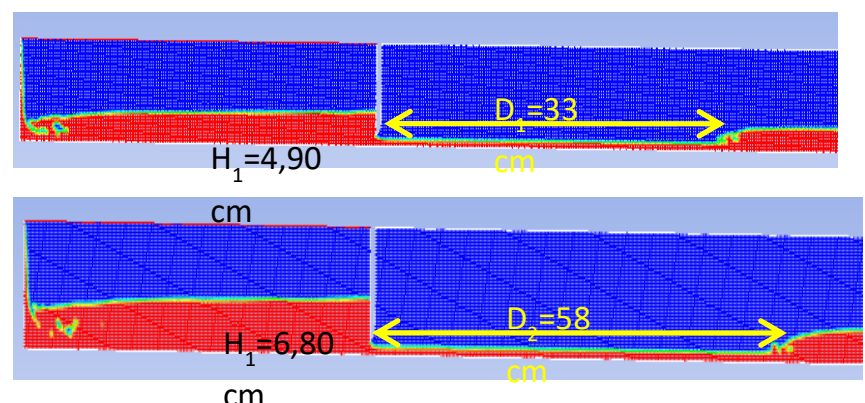

$\mathrm{cm}$

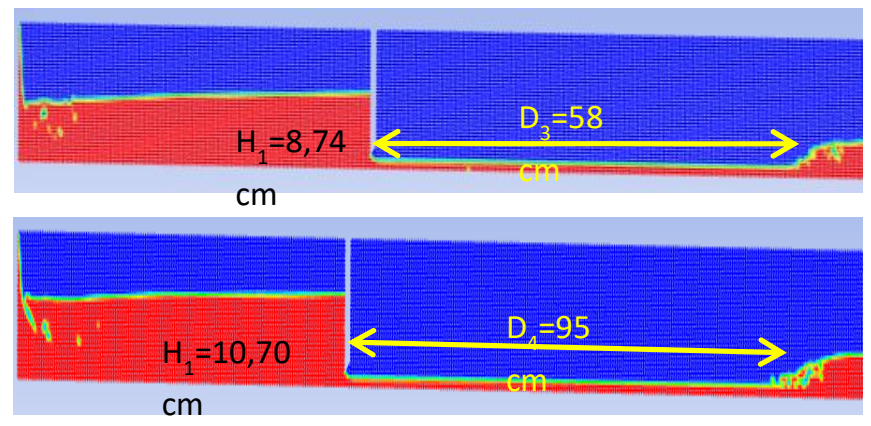

Fig. 9. Mesh and solution setup of fluent

\section{CONCLUSIONS}

As mentioned in the previous sections, an unpredictable hydraulic jump is extremely dangerous. As can be seen from the experiments, the position of the hydraulic jump varies depending on discharge and hydraulic conditions such as discharge, the geometry of the channel, and position of the step. The location of the hydraulic jump will occur should 
be estimated correctly and additional precautions should be taken. In this study, numerical modeling programs such as Fluent

\section{REFERENCES}

[1] CHOW, W. T., Open Channel Hydraulics, McGraw Hill Publications, Japan, 1959.

[2] INTERNATIONAL COMMISSION OF LARGE DAMS, Dam Failures and Statistical Analysis, ICOLD bulletin 99, Paris, France, 1995, p. 75-80. https://www.icoldcigb.org/GB/publications/bulletins.asp

[3] FIEDLER, W.R., Case Histories - Spillway Gates: Folsom Dam Radial Gates. Dam Failures and Lessons Learned Seminar, Denver: Federal Emergency Management Agency. https://damfailures.org/case-study/folsom-damcalifornia-1995/.

[4] GHARANGIK, A.M., CHAUDHRY, M.H., J. of Hyd. Eng. ASCE, 117, no. 9, 1991, p. 1195, https://doi.org/10.1061/(ASCE)07339429(1991)117:9(1195). show that it can predict the position of hydraulic jump correctly.

[5] EAD, S. A., RAJARATNAM, N., J. of Hyd. Eng. ASCE, 128, no. 7, 2002, p. 656, https://doi.org/10.1061/(ASCE)07339429(2002)128:7(656).

[6] SARKER, M. A. RHODES, D. G., Physical Modeling and CFD Applied to Hydraulic Jumps, Cranfield University Report, 2002.

[7] YUNUS, A. Ç., JOHN M. C., Fluid Mechanics Fundamentals and Applications, McGraw Hill, New York, 2006, p. 679-724.

[8] ANSYS Academic Research Mechanical, Help System, Coupled Field Analysis Guide, ANSYS,

Inc, https://www.ansys.com/products/fluids/ansysfluent. 